\title{
Performance Enhancement of Double Tube Heat Exchanger Using Coiled Fins
}

\author{
A. Khalil ${ }^{1}$, S. A. El-Agouz ${ }^{2}, \quad$ A. E. Zohir ${ }^{3}, \quad$ A. M. Farid ${ }^{4}$ \\ ${ }^{1}$ Mechanical Engineering Department, Tanat University, akhalileg@yahoo.com \\ ${ }^{2}$ Mechanical Engineering Department, Tanat University, elagouz2011@yahoo.com \\ ${ }^{3}$ Mech. Engineering Dep., Tabbin Institute for Metallurgical Studies, alaa_sadegh@yahoo.com \\ ${ }^{4}$ Mech. Engineering Dep., Tabbin Institute for Metallurgical Studies, farid_ayman_82@yahoo.com
}

\begin{abstract}
The effect of inserting coil wire in the shell side of a double pipe heat exchanger on the heat transfer and pressure drop are experimentally investigated. The experiments are performed using water as the hot and cold working fluid under the turbulent flow condition. Nine coils with different wire diameter $\left(d_{w}=2,4\right.$ and $6 \mathrm{~mm})$ and different coil pitch ratio $\left(P / d_{w}=2.5,5\right.$ and 7.5) are used in the study. Results presented an increasing up to 1.59 in the heat transfer coefficient while the pressure drop increased 10 times compared with the smooth pipe. Results also showed that the increase in the heat gain is very big than the loss in the pumping power.
\end{abstract}

\section{INTRODUCTION}

The heat exchanger is the main part of most industry So many efforts made by the researcher to improve its efficiency. The motivation of this work was the increasing of energy price due to the limitation of energy sources and raw material. Also the rapid growth of heat transfer load in the industry. Methods used can be divided into active and passive. In active techniques, some external power needed to enhancement the heat transfer like pulsating flow, magnetic fields and surface vibration. Passive methods the heat transfer improves by redeveloped the thermal boundary layer and introduce turbulence which make a good mixing to the fluid. The passive method such as twisted tape, a helical screw, coil tube, corrugated pipes and coil inserts. Methods used to enhancement heat transfer rate and the efficiency led to complicate the design and affected the pressure drop. So experimental and numerical analyses should be done to compare the benefits of high heat transfer rate with an increase in pumping power to overcome the frictions loss for any methods use.

Coil wire insert is one of the passive techniques which is widely used in heat transfer application, like heat recovery, boiler, air conditioning, chemical reactor and food process. This is due to its low cost, easy to install and possible to any smooth pipe. Inserting the coil - wire inside smooth tube enhancement the heat transfer rate for one or more reasons as follow:

1) Coil attached to pipe act as roughness element causes fluid separation near the wall and destroy the boundary layer, increasing the turbulence motion.

2) Coil wire produces a helical flow (swirl flow) that make a good mixing to the fluid.
3) The wire attached to the tube increases the wetted perimeter and surface area.

4) Inserting coil - wire inside the tube decreases the hydraulic diameter and increasing the flow velocity.

Many researchers discuss the effect of Inserting coil wire on heat transfer rate Garcia et al. [1] experimentally studied the heat transfer enhancement in a circular tube fitted with coil wire in laminar - transition and turbulent flow. They used six different wire coil geometry in their studied $[1.17<\mathrm{p} / \mathrm{d}<2.68$, $0.07<\mathrm{e} / \mathrm{d}<0.1]$. The fluid used in the experiment was water with propylene glycol. Result showed that at laminar flow there was no change while at turbulent flow the heat transfer increased with the high pressure-drop. The best result was at transition region where heat transfer increased up to $200 \%$ with the same pumping power. Gracia et al. [2] tested the effect of coil pitch on the heat transfer and pressure drop through a tube in laminar and transition flow. They found that the friction factor increased by 5: $40 \%$ in laminar flow when the coil was used. For heat transfer, they investigated that at Re less than 200 there was no significant change. While for laminar flow $200<\operatorname{Re}>1000$ there was a remarkable increase in heat transfer due to coil wire inserted. For transitional flow at $\mathrm{Re}$ around 1000 the heat transfer was about 8 times higher than smooth pipe. They also compared their results with twisted tape result and found that, at Re ranged between 700: 2500 using coil wire was better than twisted tape.

Naphon [3] inserted coil - wire in double pipe heat exchanger and tested its effect on thermal performance. He used two coils with the same diameter and different pitch at different flow rate for hot and cold sides. Results showed that using coil wire inserted had enhancement heat transfer rate. This enhancement was decreased as Reynold number increased. Coil wire inserted in a double pipe heat exchanger used to heating engine oil was investigated by Behabadi et al.[4]. They examined seven different coil with diameter (2 and $3.5 \mathrm{~mm}$ ) and different coil pitch. According to the performance, the coil with small diameter was the best coil while coil pitch had no significant effect. Promvonge [5] tested the effect of a coil wire inserted with snail as swirl generator at the performance of turbulent air flow inside a uniform heat flux tube. Two different cross section, square and circular wire, was used with a constant pitch. Results showed that using coil wire with snail entrance increased the heat transfer rate by 3.4: 3.9 compared with smooth pipe. It 
also showed that using square wire cross section had higher performance about 10: $15 \%$ than circular wire.

Dizaji et al.[6] examined experimentally the effect of corrugated tube on the heat transfer and pressure drop characteristics in double pipe heat exchanger. They used water only as a working fluid. They studied different arrangement of corrugation, concave (inward corrugation) and convex (outward corrugation), for both the inner and outer pipe. The result showed that the maximum enhancement in the heat transfer was obtained for concave the outer tube and convex the inner one. The effect of geometry of a corrugated tube on the thermal performance of a tube in tube heat exchanger was studied experimentally by Pethkool et al. [7]. They examined different pitch to diameter ratio and different rib- height to diameter ratio for turbulent flow. They found that the thermal performance and pressure drop increased with increasing the pitch ratio and rib height ratio. Rozzi et al. [8] compared between using smooth and corrugated tube in shell and tube heat exchanger in food industry. They tested Newtonian fluid (whole milk and orange juice) and non - Newtonian (Apricot and Apple puree). They found that at $\mathrm{Re}<800$ there was negligible change while at laminar flow $\operatorname{Re}>800$ and transitional flow a significant heat transfer enhancement was achieved. They also observed a moderate enhancement for turbulent flow with a very high friction factor banality.

Gunes et al [9], Keklikcioglu and Ozceyhan [10] studied the triangular cross section wire as tubular coil inserted in tube at its thermal performance. The coil was separated from the tube wall by a Teflon rang. They tested the effect of pitch ratio and side length. Results showed that, Nusselt number increased with pitch ratio decreased and wire thickness increased. Also the highest enhancement efficiency was observed at low Reynold number. More heat transfer enhancement can be achieved when the coil was oriented to face the flow. In another experimental work Gunes et al [11], Keklikcioglu and Ozceyhan [12] examined the effect of the separated distance between the coil and tube wall on the heat transfer rate. Two different distance was used $(\mathrm{S}=1$ and 2 $\mathrm{mm}$ ) with $6 \mathrm{~mm}$ coil side and pitch ratio 1,2 and 3 . They found that, thermal performance increased with distance decreased because it increased the turbulence in the fluid field and interrupted the development of the laminar boundary layer.

Hong et al [13] studied the effect of the coil wire pitch and width inserted through pipe on the heat transfer rate under constant heat flux condition. They tested six coil with uniform and varied pitch ratio and variable width. The fluid used in their work was air with Reynolds number varied from 6000 and 20000. Results indicated that, using coil wire increased the thermal performance up to 1.14 with uniform coil pitch $\mathrm{p} / \mathrm{d}=1.034$. Also, using of varied pitch coil or coil with varied width coil had no further improvement than uniform pitch coil. Experimental work was done by Zohir et al [14] using insulated wire coil on the outer surface of the inner tube as turbulator and studied its effect on the heat transfer rate. The coils used had $2 \mathrm{~mm}$ diameter and pitch, $\mathrm{P}=6,12$ and $20 \mathrm{~mm}$. Also counter and parallel flow arrangement was tested. It was found from results that, counter flow was better than parallel flow. Also, the heat transfer coefficient increased with increasing Reynold number and coil pitch. In another work Zohir et al [15] coil wire inserted in pulsating flow to investigate its effect on the performance of heat exchanger. Insulated coil with different pitch $(\mathrm{P}=6,12$ and $20 \mathrm{~mm})$ was used. They observed a maximum average Nusselt number 12.7 time than smooth pipe at $20 \mathrm{~mm}$ pitch and high pulsating with low Reynold number. This increasing in Nusselt number was accompanied by an increasing in pressure loss by 8.7 time at the same condition. Panahi and Zamzamian [16] inserted the coil wire as turbulator in shell and coil heat exchanger and investigated its effect on the performance at different flow rate. They tested water / air as a cold fluid flow inside coil and hot water at the shell side. They found that, coil wire can be used in helical tube which increasing the heat transfer rate with noticeably extra pressure loss. Eiamsa-ard et al.[17] made an experimental work using a combination between coil and twisted tape and studied its effect on the heat transfer coefficient and pressure drop. They used coil with uniform or varied pitch ratio. They notice that, using coil with decreased increased pitch had higher heat transfer rate than any other arrangement tested in their study.

In the above publication, most studies focused on the effects of inserting coil wire inside tube on the heat transfer and friction of air or water in laminar and turbulent flow. The aim of our work is to investigate the effects of coiled wires wounded at the outer surface of the inner tube of a double tube heat exchanger with different coil pitch and different wire diameter on heat transfer rates and pressure drop. The investigation is performed for turbulent cold water flows with Reynolds numbers ranging from 5,000 to 25,000 and counter flows hot water in the shell side. Ten different test rig with or without coiled wire is used.

\section{EXPERIMENTAL WORK}

The test facility used in this work is shown in fig 1 and 2 . It consists of a double tube counter flow heat exchanger. The inner tube made of copper has $16 \mathrm{~mm}$ inner diameter and 19 $\mathrm{mm}$ outer diameter. The outer tube is a PVC tube with 76.2 $\mathrm{mm}$ inner diameter. The effective length of the test section is $2000 \mathrm{~mm}$. the dimension was chosen to have a fully developed and forced convection. The outer pipe is covered with a layer of glass wool as insulation to minimize heat loss to the environment. Ten heat exchanger was constructed with different coil. Coil was made of copper wire with diameter $\mathrm{d}_{\mathrm{w}}$ $=2,4$ and $6 \mathrm{~mm}$. each coil wounded carefully at the outer surface of the inner tube to ensure good contact and fixed pitch between coil and surface. The coil pitch was $P=2.5 d_{w}, 5 d_{w}$ and $7.5 \mathrm{~d}_{\mathrm{w}}$. A photograph for the coil wounded on the tube surface are shown in Fig. 3. Four k type thermocouple was mounted at the outer surface of the inner tube to measure its surface temperature with equal uniform spacing. Both inlet and outlet temperatures of the cold and hot water measured using $\mathrm{K}$-type thermocouples, calibrated within $\pm 0.5 \% \mathrm{C}$ deviation by an Ultra thermostat before being used. The signal outputs of thermocouples were indicated by a data logger device (GL800-UM-851 midi logger), which has an accuracy of $\pm 0.05 \%$ of reading for K-type thermocouple. Cold water flows in the inner tube with Reynolds number varied from 5000 to 25000 . The cold water has a $50-$ liter plastic tank. The fluid is tapped from the bottom of the tank by $0.5 \mathrm{hp}$ pump. A bypass connection is used to control the flow rate through the test section. The cold fluid gain heat from the heat exchanger and return to the tank. Flow meter uses to measure the flow 
Vol. 1 - 2019

rate in the exit pipe before entering the tank to ensure that fluid is filling up the tube. Two cooling units in parallel with 1.5 $\mathrm{kW}$ was used to keep the inlet temperature of cold water between $20-30{ }^{\circ} \mathrm{c}$. We use water as a hot fluid in the heat exchanger. For this purpose, a hot water tank 50 liter galvanized steel is used. A temperature control unit consists of two heater $2 \mathrm{~kW}$ each, k-type thermocouple and (TC4 temperature control) unit applied to keep the fluid at required temperature inside tank. The hot water tapped out from the

\section{Engineering Research Journal}

bottom of the tank and pumped through the annuals pipe of the test section with inlet temperature around $70{ }^{\circ} \mathrm{c}$. The low temperature fluid out from the heat exchanger returned back to the tank. The hot water flow rate has $\operatorname{Re}=5000$ and control using a by-pass pipe after pump and measured with flow meter in the returned connection before entering the hot tank. (H12 liquid manometer) was used to measure the pressure drop in the both side of the heat exchanger

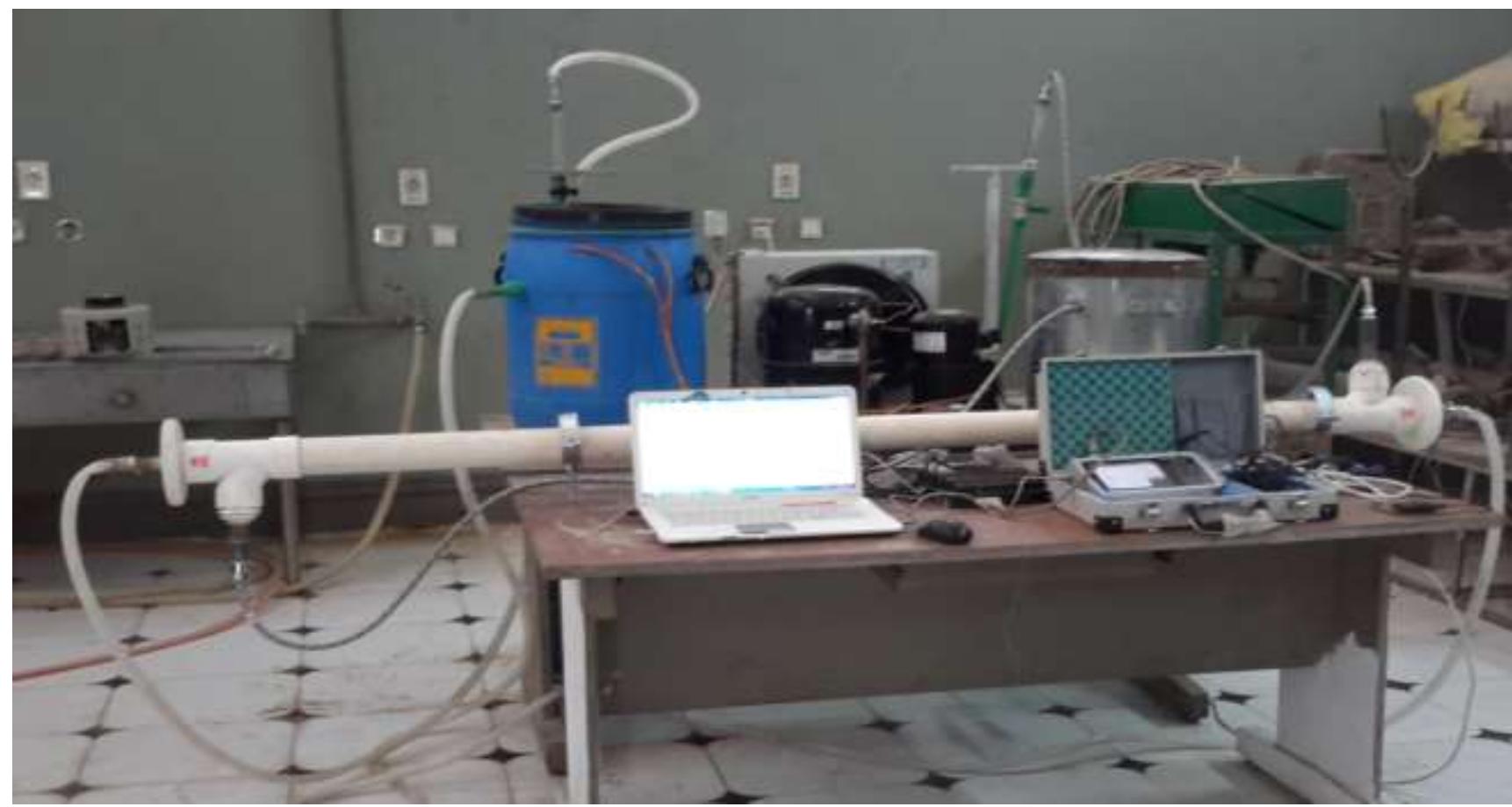

Figure 1. Photograph of an experimental setup.

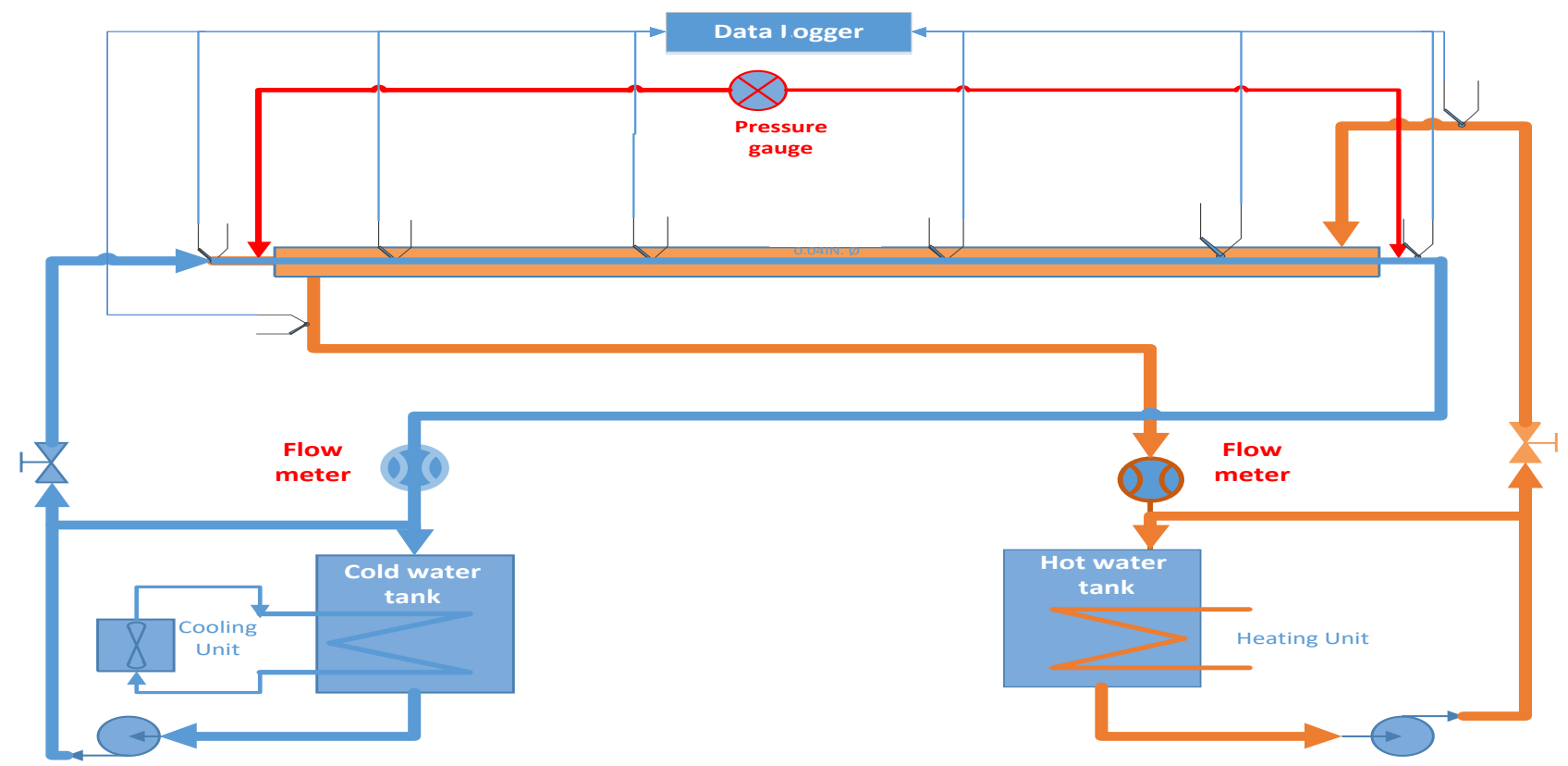

Figure 2. Schematic of the experimental setup and instrumentation. 


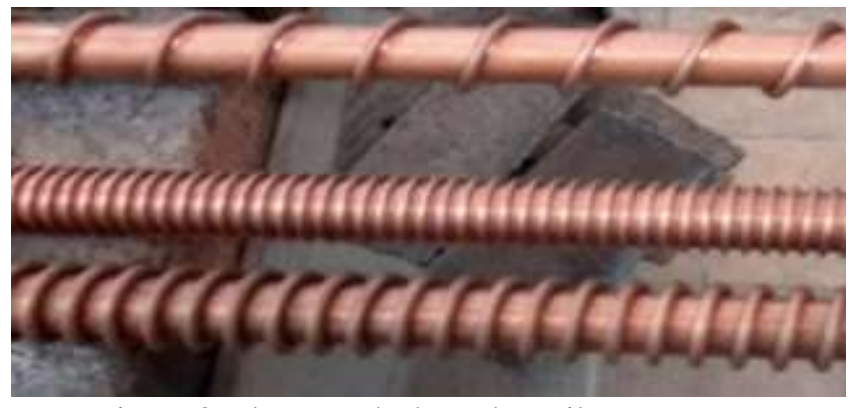

Figure 3. Photograph show the coil parameter.

\section{DATA REDUCTION}

In the present work, the data reduction comprised the overall heat transfer coefficient (U), Reynold number, pressure drop, power loss and effectiveness.

The heat transfer from the hot fluid and gained in the cold one and average between them is calculated as follow:

$$
\begin{gathered}
Q_{h}=m_{h} c_{p_{h}}\left(T_{h_{i}}-T_{h_{o}}\right) \\
Q_{c}=m_{c} c_{p_{c}}\left(T_{c_{o}}-T_{c_{i}}\right) \\
Q_{\text {avg }}=\frac{Q_{h}+Q_{c}}{2} \\
Q_{\text {avg }}=U A \Delta T_{l m} \\
\Delta T_{l m}=\frac{\left(\Delta T_{i n}-\Delta T_{o}\right)}{\ln \left(\Delta T_{i n} / \Delta T_{o}\right)}
\end{gathered}
$$

Where $\Delta T_{\text {in }}=T_{h_{i}}-T_{c_{o}}$ and $\Delta T_{o}=T_{h_{o}}-T_{c_{i}}$

Where $\mathrm{U}$ is the overall heat transfer coefficient can be calculated from equation (4) as follow

$$
U=\frac{Q_{a v g}}{A \Delta T_{l m}}
$$

Reynolds number calculated using the mass flow rate measured by the floating flow meter as follow:

$$
R e=\frac{\rho u d}{\mu}=\frac{4 m}{\pi d \mu}
$$

The required pumping power needed to overcome the loss due to the pipe friction and coil wire inserting for both side is calculated from the equation:

$$
\text { Power loss }=\frac{m \cdot \Delta P}{\rho}
$$

Where $\Delta \mathrm{P}$ is measured using pressure gauge.

The effectiveness of the heat exchanger is calculated using:

$$
\varepsilon=\frac{Q_{a v g}}{Q_{\max }}=\frac{Q_{a v g}}{\left(m \cdot c_{p}\right)_{\min }\left(T_{h_{i}}-T_{c_{i}}\right)}
$$

Where $\left(m \cdot c_{p}\right)_{\text {min }}=\left(m \cdot c_{p}\right)_{c}$ at $\operatorname{Re}<20000$ and $\left(m \cdot c_{p}\right)_{\text {min }}$ $=\left(m \cdot c_{p}\right)_{h}$ at $\operatorname{Re} \geq 20000$.

\section{RESULT AND DISCUSSION}

The aim of our work is to experimentally investigate the effect of inserting coil wire in the annulus pipe of counter flow heat exchanger. Fifty experimental was done with different pitch and different diameter for the coil in this study. The change in the overall heat transfer coefficient is presented in Figs (4-9). As shown in all figures the heat transfer rate increased with inserting the coil compared with smooth pipe. This increasing has the same trend as smooth, the heat transfer increase with Reynold number increase. This due to the turbulence that coil wire induced which causes separation and reattachment region around the tube surface and destroy the boundary layer. Coil also increased the tube heat transfer surface area. In Figs (4-6), the effect of coil pitch on the heat transfer coefficient at constant coil diameter and different Reynold number is shown. It's clear from fig. that the heat transfer increased with the pitch ratio increased for coil diameter $2 \mathrm{~mm}$ and $4 \mathrm{~mm}$. while at coil diameter $6 \mathrm{~mm}$ it decreased with the coil pitch increased due to the decreasing in the surface area. The effect of coil diameter at constant pitch ratio presented at Figs (7-9). The overall heat transfer coefficient increased up to 1.59 for coil diameter $4 \mathrm{~mm}$ at pitch ratio 7.5 while the maximum value for coil diameter 2 $\mathrm{mm}$ and $6 \mathrm{~mm}$ was 1.53 and 1.38 respectively.

Figs (10-15) show the effect of inserting coil wire at the effectiveness of the heat exchanger. For coil diameter $2 \mathrm{~mm}$ the effectiveness increased with pitch ratio increased. While for coil diameter 4 and $6 \mathrm{~mm}$, it increased with pitch ratio increased till pitch ratio 5 then it decreased with increasing the pitch ratio. Coil diameter has an insignificant effect at low pitch ratio on the effectiveness as presented in Fig (13). But at pitch ratio 5 and 7.5 the coil with $4 \mathrm{~mm}$ diameter has higher effectiveness up to 1.48 and it was 1.39 and 1.31 for coil diameter 2 and $6 \mathrm{~mm}$ respectively.

\section{Pressure drop}

The effect of coil wire on the pressure drop is shown in Figs (16-21). It's clear from figures that inserting the coil wire increasing the pressure drop up to 10 times at coil diameter 6 $\mathrm{mm}$ and pitch ratio 2.5 . The pressure drop increased with wire diameter increased and pitch ratio decreased.

But the increase in the heat gain due to inserting the coil wire in the heat exchanger can't be compared with the small increasing in the pumping power as shown in figure (22). 


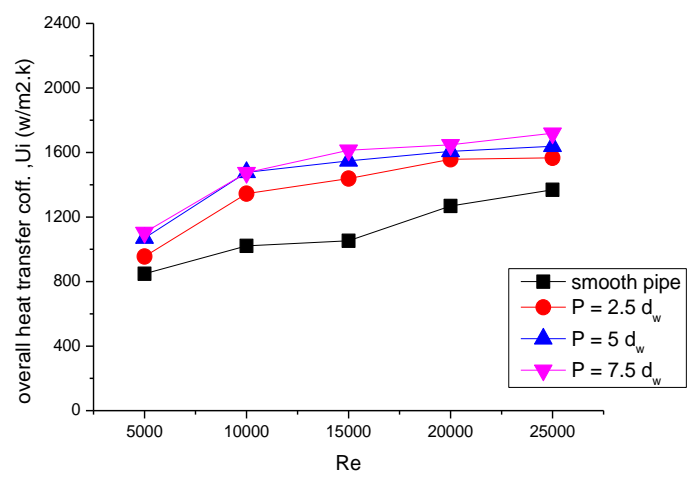

Figure 4. The effect of coil pitch on the overall heat transfer coefficient for coil diameter $2 \mathrm{~mm}$

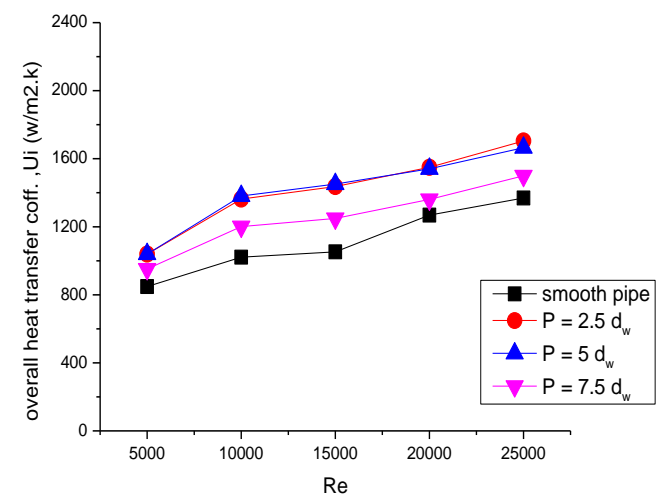

Figure 6. The effect of coil pitch on the overall heat transfer coefficient for coil diameter $6 \mathrm{~mm}$

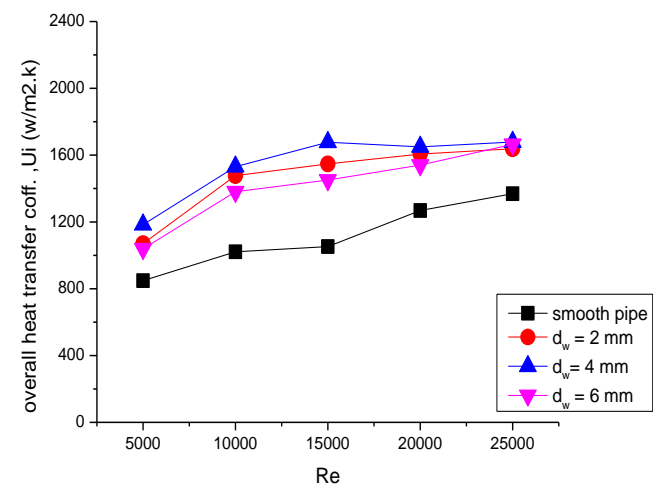

Figure 8 . The effect of coil diameter on the overall heat transfer coefficient for coil pitch $\mathrm{P}=5 \mathrm{~d}_{\mathrm{w}}$

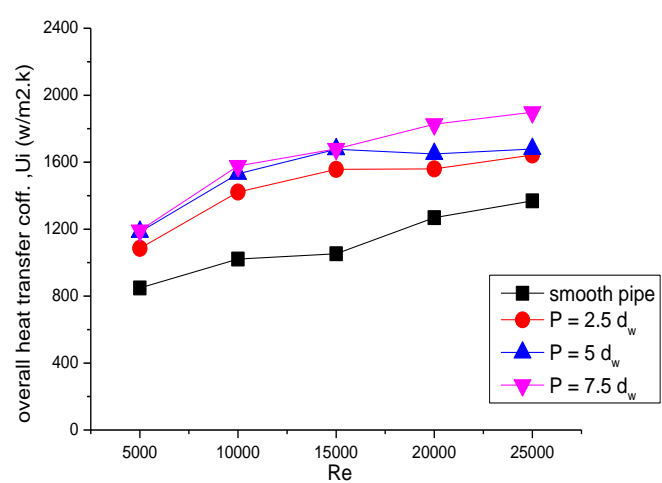

Figure ${ }^{\circ}$. The effect of coil pitch on the overall heat transfer coefficient for coil diameter $\leqslant \mathrm{mm}$

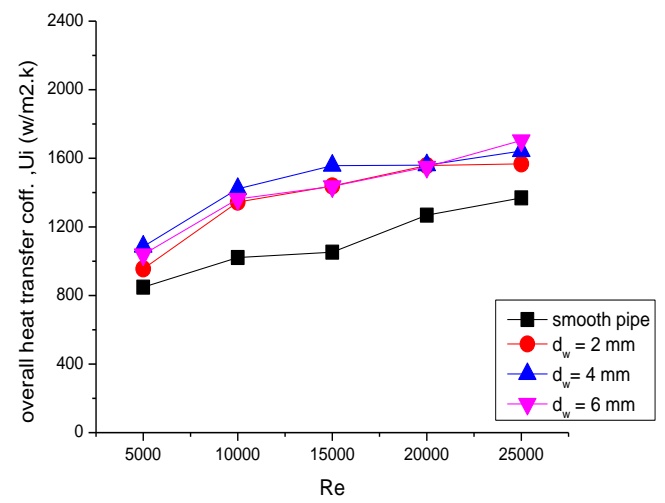

Figure 7. The effect of coil diameter on the overall heat transfer coefficient for coil pitch $\mathrm{P}=2.5 \mathrm{~d}_{\mathrm{w}}$

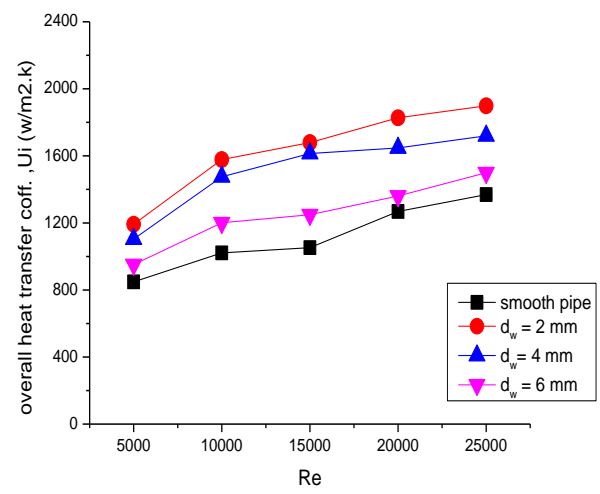

Figure 9. The effect of coil diameter on the overall heat transfer coefficient for coil pitch $\mathrm{P}=7.5 \mathrm{~d}_{\mathrm{w}}$ 


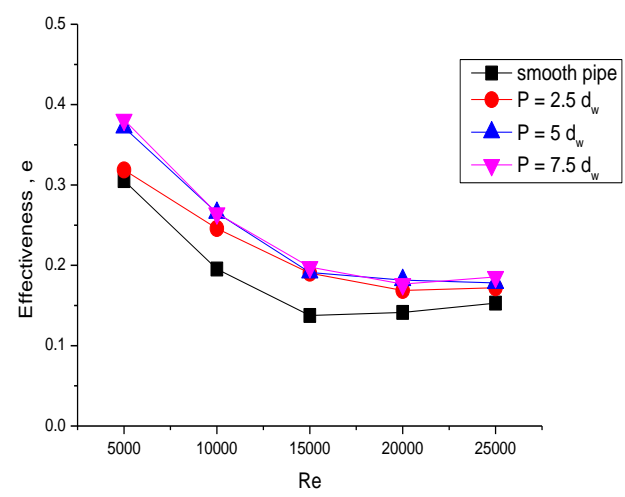

Figure 10. The effect of coil pitch on the effectiveness of the heat exchanger for coil diameter $2 \mathrm{~mm}$

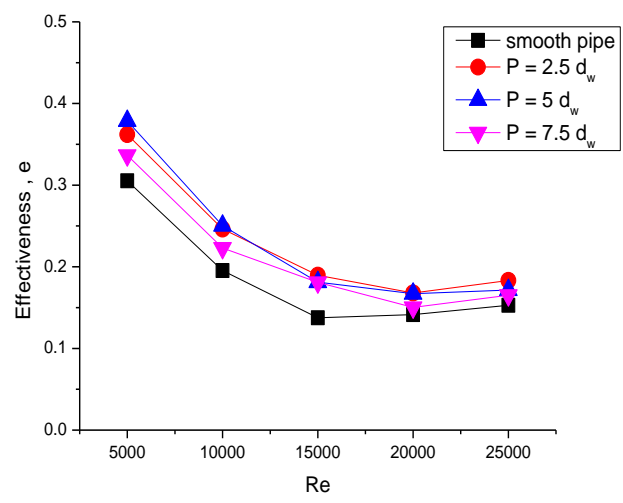

Figure 12. The effect of coil pitch on the effectiveness of the heat exchanger for coil diameter $6 \mathrm{~mm}$

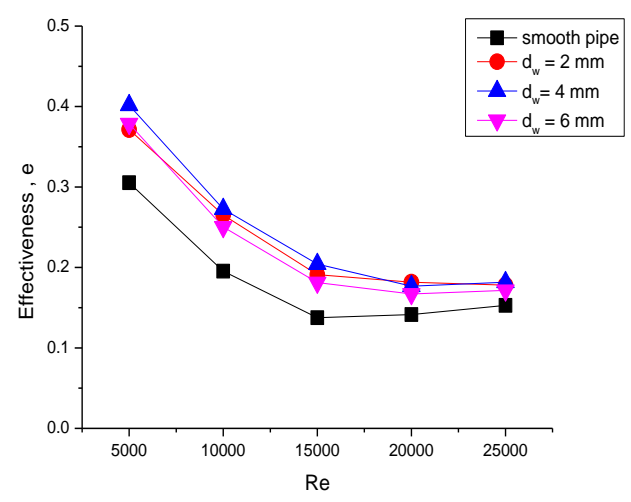

Figure 14. The effect of coil diameter on the effectiveness of the heat exchanger for coil pitch $P=5 d_{w}$

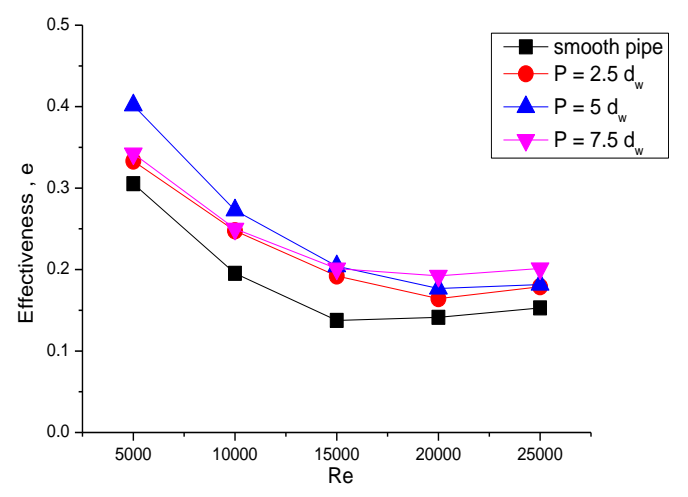

Figure 11. The effect of coil pitch on the effectiveness of the heat exchanger for coil diameter $4 \mathrm{~mm}$

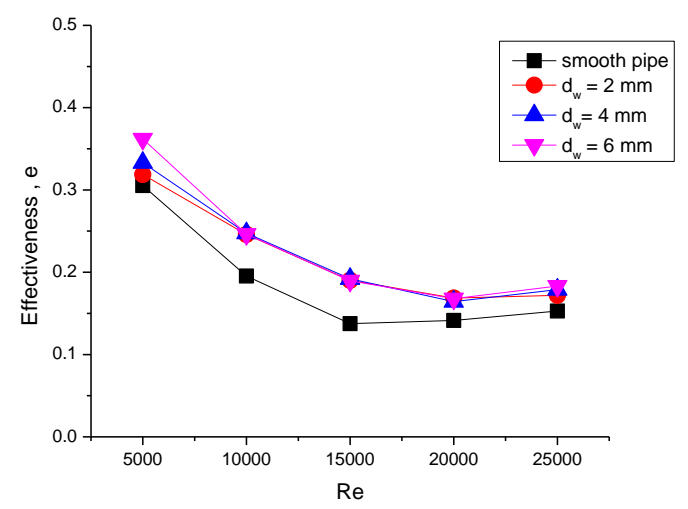

Figure 13. The effect of coil diameter on the effectiveness of the heat exchanger for coil pitch $P=2.5 d_{w}$

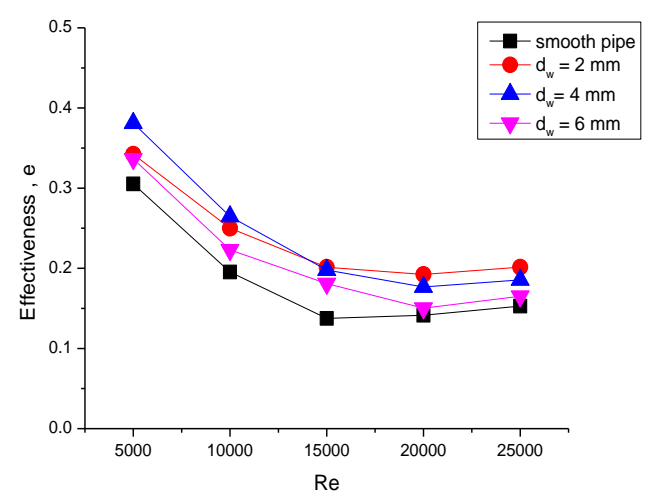

Figure 15. The effect of coil diameter on the effectiveness of the heat exchanger for coil pitch $\mathrm{P}=7.5 \mathrm{~d}_{\mathrm{w}}$ 

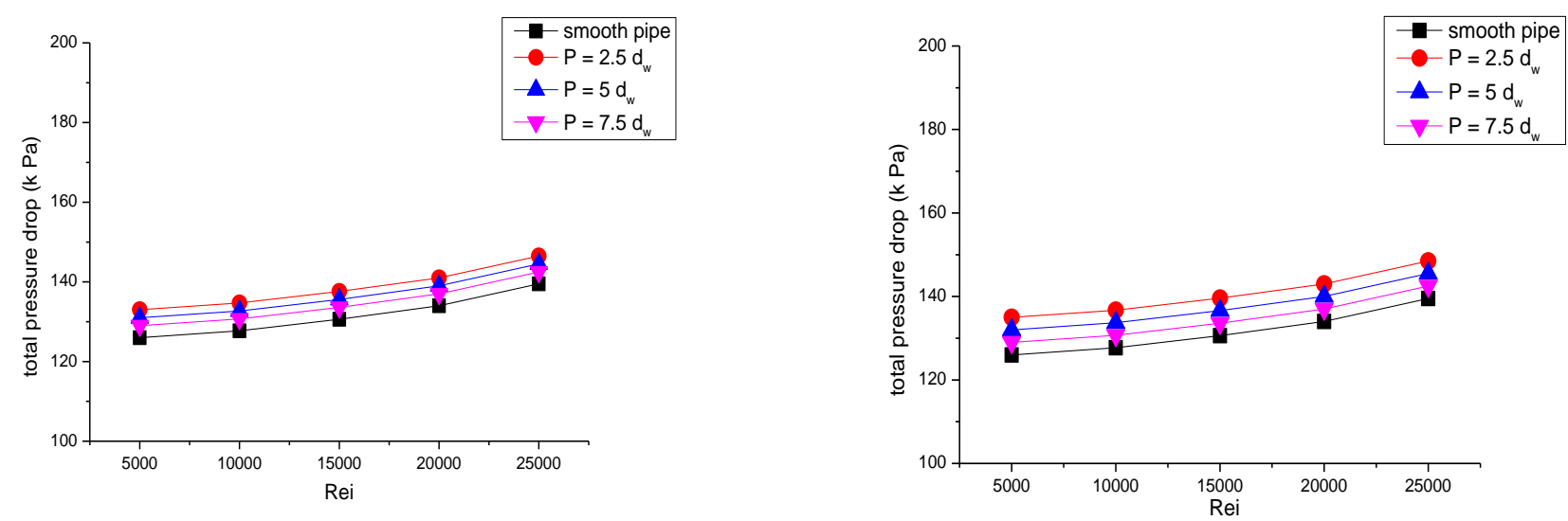

Figure 16. The effect of coil pitch on the pressure drop for coil diameter $2 \mathrm{~mm}$

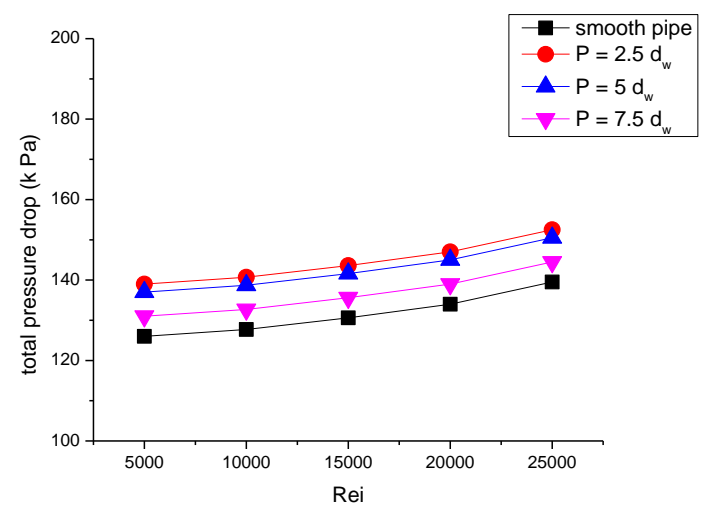

Figure 18. The effect of coil pitch on the pressure drop for coil diameter $6 \mathrm{~mm}$

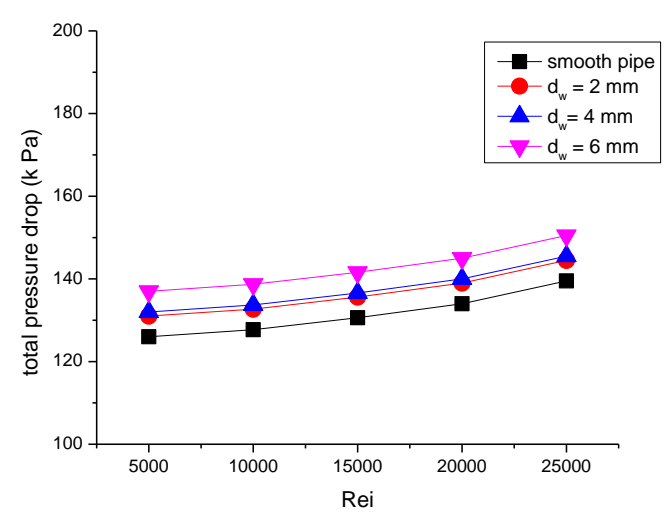

Figure 20. The effect of coil diameter on the pressure drop for coil pitch $=5 \mathrm{~d}_{\mathrm{w}}$
Figure 17. The effect of coil pitch on the pressure drop for coil diameter $4 \mathrm{~mm}$

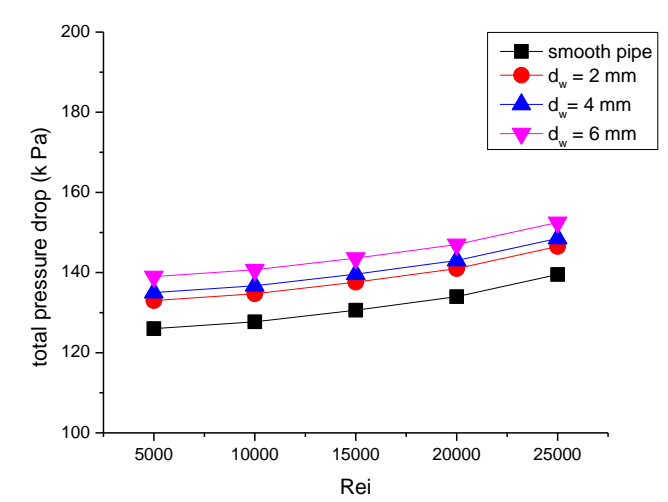

Figure 19. The effect of coil diameter on the pressure drop for coil pitch $=2.5 \mathrm{~d}_{\mathrm{w}}$

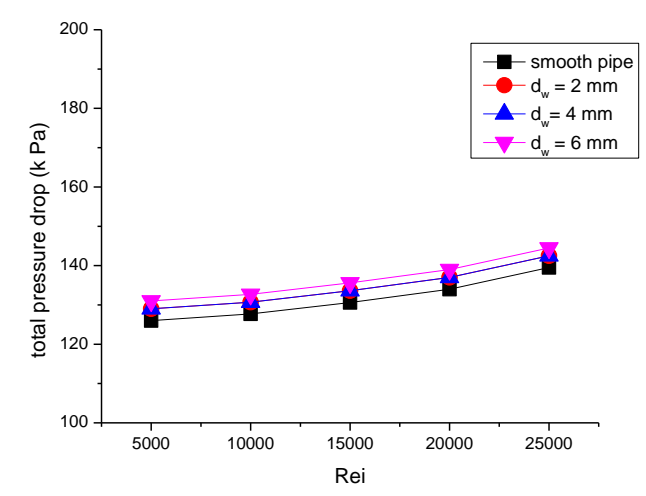

Figure 21. The effect of coil diameter on the pressure drop for coil pitch $=7.5 \mathrm{~d}_{\mathrm{w}}$ 


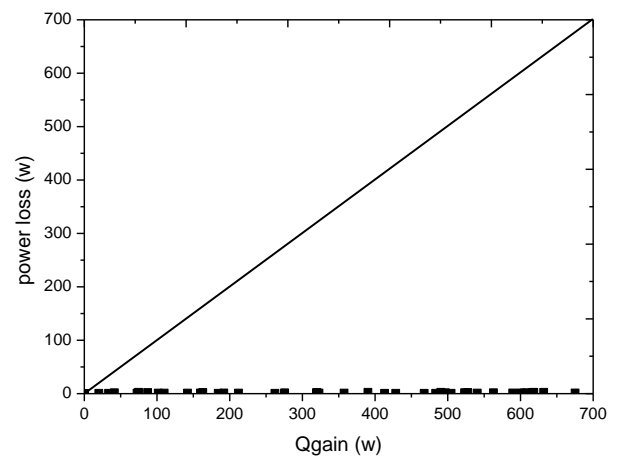

Figure 22. comparison between power gain in heat transfer and power loss in pumping

\section{CONCLUSION}

Experimental work has done to investigate the heat transfer rate and pressure drop for a double pipe heat exchanger fitted with coil wire inserted in the shell side. It's observed that:

1. The heat transfer rate increased with Reynolds number increase.

2.For coil diameter 2 and $4 \mathrm{~mm}$, the heat transfer coefficient increased with the coil pitch ratio increased while it decreased with the pitch ratio increased at coil diameter $6 \mathrm{~mm}$.

3.The effect of coil diameter, the heat transfer increased with coil diameter increased unit $4 \mathrm{~mm}$ then it decreased with coil diameter increased.

4. The pressure drop increased with coil diameter increased and pitch ratio decreased.

5.The increase in the heat transfer gain is higher than the loss in pumping power.

\section{Nomenclature}

$C_{p} \quad$ Specific heat capacity of the fluid, J/kg.K

$d \quad$ Wire diameter, $\mathrm{m}$

D Inner Pipe diameter, $\mathrm{m}$

T Temperature, ${ }^{\circ} \mathrm{C}$

$h \quad$ Heat transfer coefficient, W/m2.K

p Coil pitch, $\mathrm{m}$

$K \quad$ Thermal conductivity of the fluid, W/m.K

$\mathrm{Nu} \quad$ Nusselt number

$\Delta P \quad$ Pressure drop, $\mathrm{Pa}$

Re Reynolds number

$Q \quad$ Heat transfer rate, $\mathrm{W}$

Greek Symbols

$\eta \quad$ Efficiency

$\rho \quad$ Density, $\mathrm{kg} / \mathrm{m} 3$

$\mu \quad$ Viscosity of the fluid, N.s/m2

Subscripts

$w \quad$ wire

$i$ inlet

$o \quad$ Outlet

c cold

$h$ hot

\section{Reference}

[1] A. Garcia, P. G. Vicente, and A. Viedma, "Experimental study of heat transfer enhancement with wire coil inserts in laminar-transition-turbulent regimes at different Prandtl numbers," International Journal of Heat and Mass Transfer, vol. 48, pp. 4640-4651, 2005.

[2] A. Garcia, J. P. Solano, P. G. Vicente, and A. Viedma, "Enhancement of laminar and transitional flow heat transfer in tubes by means of wire coil inserts," International Journal of Heat and Mass Transfer, vol. 50, pp. 3176-3189, 2007.

[3] P. Naphon, "Effect of coil-wire insert on heat transfer enhancement and pressure drop of the horizontal concentric tubes," International Communications in Heat and Mass Transfer, vol. 33, pp. 753-763, 2006.

[4] M. Akhavan-Behabadi, R. Kumar, M. Salimpour, and R. Azimi, "Pressure drop and heat transfer augmentation due to coiled wire inserts during laminar flow of oil inside a horizontal tube," International Journal of Thermal Sciences, vol. 49, pp. 373-379, 2010.

[5] P. Promvonge, "Thermal enhancement in a round tube with snail entry and coiled-wire inserts," International Communications in Heat and Mass Transfer, vol. 35, pp. 623-629, 2008.

[6] H. S. Dizaji, S. Jafarmadar, and F. Mobadersani, "Experimental studies on heat transfer and pressure drop characteristics for new arrangements of corrugated tubes in a double pipe heat exchanger," International Journal of Thermal Sciences, vol. 96, pp. 211-220, 2015.

[7] S. Pethkool, S. Eiamsa-Ard, S. Kwankaomeng, and P. Promvonge, "Turbulent heat transfer enhancement in a heat exchanger using helically corrugated tube," International Communications in Heat and Mass Transfer, vol. 38, pp. 340-347, 2011.

[8] S. Rozzi, R. Massini, G. Paciello, G. Pagliarini, S. Rainieri, and A. Trifiro, "Heat treatment of fluid foods in a shell and tube heat exchanger: Comparison between smooth and helically corrugated wall tubes," Journal of food engineering, vol. 79, pp. 249-254, 2007.

[9] S. Gunes, V. Ozceyhan, and O. Buyukalaca, "Heat transfer enhancement in a tube with equilateral triangle cross sectioned coiled wire inserts," Experimental Thermal and Fluid Science, vol. 34, pp. 684-691, 2010.

[10] O. Keklikcioglu and V. Ozceyhan, "Experimental investigation on heat transfer enhancement in a circular tube with equilateral triangle cross sectioned coiled-wire inserts," Applied Thermal Engineering, vol. 131, pp. 686-695, 2018.

[11] S. Gunes, V. Ozceyhan, and O. Buyukalaca, "The experimental investigation of heat transfer and pressure drop in a tube with coiled wire inserts placed separately from the tube wall," Applied Thermal Engineering, vol. 30, pp. 1719-1725, 2010.

[12] O. Keklikcioglu and V. Ozceyhan, "Experimental investigation on heat transfer enhancement of a tube with coiled-wire inserts installed with a separation from the tube wall," International Communications in Heat and Mass Transfer, vol. 78, pp. 88-94, 2016.

[13] Y. Hong, J. Du, S. Wang, S.-M. Huang, and W.-B. Ye, "Heat transfer and fluid flow behaviors in a tube with 
Vol. 1 - 2019

modified wire coils," International Journal of Heat and Mass Transfer, vol. 124, pp. 1347-1360, 2018.

[14] A. Zohir, M. Habib, and M. Nemitallah, "Heat transfer characteristics in a double-pipe heat exchanger equipped with coiled circular wires," Experimental heat transfer, vol. 28, pp. 531-545, 2015.

[15] A. Zohir, A. A. A. Aziz, and M. Habib, "Heat transfer characteristics and pressure drop of the concentric tube equipped with coiled wires for pulsating turbulent flow," Experimental Thermal and Fluid Science, vol. 65, pp. 41-51, 2015.

\section{Engineering Research Journal}

[16] D. Panahi and K. Zamzamian, "Heat transfer enhancement of shell-and-coiled tube heat exchanger utilizing helical wire turbulator," Applied Thermal Engineering, vol. 115, pp. 607-615, 2017.

[17] S. Eiamsa-Ard, P. Nivesrangsan, S. Chokphoemphun, and P. Promvonge, "Influence of combined non-uniform wire coil and twisted tape inserts on thermal performance characteristics," International Communications in Heat and Mass Transfer, vol. 37, pp. 850-856, 2010. 